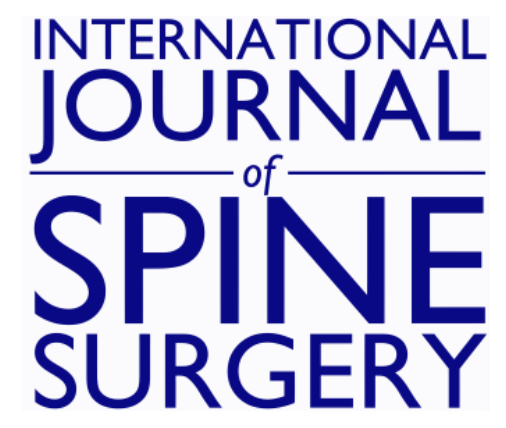

\title{
Fine grained osseointegrative coating improves biocompatibility of PEEK in heterotopic sheep model
}

Caroline M.F. Meers, Gino B.M. Verleye, Dirk Smeets, Hadewych Y.R. Van Hauwermeiren, Dirk Loeckx, Karel Willems, Vincent G.M.G.G.B. Siau and Philippe J.M.E. Lauweryns

Int J Spine Surg 2015, 9 ()

doi: https://doi.org/10.14444/2035

http://ijssurgery.com/content/9/35

This information is current as of April 26, 2023.

Email Alerts Receive free email-alerts when new articles cite this article. Sign up at:

http://ijssurgery.com/alerts

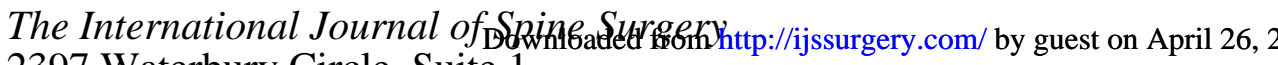
2397 Waterbury Circle, Suite 1,

Aurora, IL 60504, Phone: +1-630-375-1432

(C) 2015 ISASS. All Rights Reserved. 


\section{Fine grained osseointegrative coating improves biocompatibility of PEEK in heterotopic sheep model}

Caroline M.F. Meers, DVM, PhD, ${ }^{1}$ Gino B.M. Verleye, PhD, ${ }^{2}$ Dirk Smeets, PhD, ${ }^{3}$ Hadewych Y.R. Van Hauwermeiren, DVM, MLAS,1 Dirk Loeckx, PhD, ${ }^{3}$ Karel Willems, MD, ${ }^{4}$ Vincent G.M.G.G.B. Siau, MSc, 5 Philippe J.M.E. Lauweryns, MD, PhD 6

${ }^{1}$ Medanex Clinic, Diest, Belgium, ${ }^{2}$ Social Sciences Department, Ghent University, Ghent, Belgium, ${ }^{3}$ IcoMetrix, Leuven, Belgium, ${ }^{4}$ Department of Orthopaedic Surgery, AZ Delta, Roeselare, Belgium, 5Orthobion GmbH Konstanz, Germany, ${ }^{6}$ Department of Morphology, Hasselt University, Diepenbeek, Belgium

\section{Abstract}

Background and aim

Polyetheretherketone (PEEK) materials already have been used successfully in orthopedic and especially spine surgery. PEEK is radiolucent and comparable with bone regarding elasticity. However, PEEK is inert and the adhesion of PEEK implants to bone tissue proceeds slowly because of their relatively low biocompatibility. The aim of the study is to evaluate the effect of titanium and $\mathrm{CaP}$ coating on the adhesion of bone tissue.

\section{Material and Methods}

Six adult sheep (body weight $57.6 \pm 3.9 \mathrm{~kg}$ ) were included in this study. Three different types of cylindrical dowels (12 mm length $\times 8 \mathrm{~mm}$ diameter) were implanted in long bones (tibia and femur): PEEK dowels without coating (the control group), and PEEK dowels with a nanocoating of calcium phosphate (CaP group) or titanium (titanium group). Animals were sacrificed after 6, 12 and 26 weeks. Dowels were explanted for micro CT and histology.

Results

Bone implant contact (BIC) ratio was significantly higher in the titanium versus control groups in the 6 to 12 weeks period $(p=0.03)$. The ratio between bone volume and tissue volume (BV/TV) was significantly higher in titanium versus control in the 6 to 12 weeks period $(p=0.02)$. A significant correlation between BIC and BV/TV was seen $(\mathrm{r}=0.85, \mathrm{p}<0.05)$.

\section{Conclusion}

Coating of PEEK dowels with a nanocoating of titanium has beneficial effects on adhesion of bone tissue.

KeyWords: titanium, Bone ingrowth, Polyetheretherketone, SPINAL SURGery, Nanotopography, IN ViVo test

VOLUME 9 ARTICLE 35 - BIOMECHANICS SPECIAL ISSUE DOI: 10.14444/2035

\section{Introduction}

Until now the polyetheretherketone (PEEK) materials already have been used successfully in orthopedic and especially spine surgery. ${ }^{1}$

Peek implants are known to have good mechanical properties and elasticity, compared to other materials. ${ }^{2}$ Another great advantage of PEEK is its radiolucency. It can be imaged by X-ray, CT scan or MRI in contradiction with titanium used in these applications. ${ }^{1}$

However, the adhesion of PEEK implants to bone tissue proceeds slowly because of their relatively low biocompatibility. PEEK is an inert material and its in- tegration with bone is limited. ${ }^{3}$

The biocompatibility of the implant is strongly affected by its surface characteristics including the surface roughness, wettability and chemical composition. Therefore considerable efforts have focused on modifying the surface of the PEEK implants. ${ }^{4}$

Another way of surface modifications of the PEEK implant is the application of bioactive coating materials using various physical and chemical methods. ${ }^{5,6}$

The aim of this animal study was to combine the advantages of titanium and PEEK and to evaluate the effect on biocompatibility of nanocoating of PEEK implants with titanium and $\mathrm{CaP}$. 


\section{Materials and Methods}

Dowels

Cylindrical shaped dowels (Orthobion GmbH, Konstanz, Germany) of $12 \mathrm{~mm}$ length and $8 \mathrm{~mm}$ diameter were used for implantation. These implants have been coated with titanium and calcium phosphate $(\mathrm{CaP})$ in a unique physical nanofilm coating technique.

The thickness of the coating was $+/-275 \mathrm{~nm}$. The coating was added to the PEEK material in order to increase the bone volume; bone density and bone implant contact. The dowels were divided in two study groups: the titanium group and the $\mathrm{CaP}$ group, and a control group.

\section{Experimental groups}

Six adult, female, Swifter sheep (body weight $57.6 \pm$ $3.9 \mathrm{~kg}$ ) were included in this study. Three different types of cylindrical dowels $(12 \mathrm{~mm}$ length $\mathrm{x} 8 \mathrm{~mm}$ diameter) were implanted in long bones, femur and tibia. PEEK dowels without coating served as the control group; PEEK dowels with a nanocoating of titanium ("the titanium group") and PEEK dowels with a nanocoating of $\mathrm{CaP}$ (CaP group) served as study groups.

Two uni-cortical defects were created in both the distal lateral femur and the proximal medial tibia of left and right hind legs. This resulted in 8 defects in each sheep.

In each sheep, 2 PEEK, $3 \mathrm{CaP}$ and 3 titanium dowels were randomly implanted in tibia or femur (shown in Table 1).

\begin{tabular}{|c|c|c|c|c|c|c|}
\hline \multicolumn{7}{|c|}{ Study Design (Animals $n=6$ ) } \\
\hline \multirow{2}{*}{$\begin{array}{l}\text { Follow-up } \\
\text { Animals }\end{array}$} & \multirow{2}{*}{\multicolumn{2}{|c|}{$\begin{array}{r}6 \text { weeks } \\
n=2\end{array}$}} & \multirow{2}{*}{\multicolumn{2}{|c|}{$\begin{array}{r}12 \text { weeks } \\
n=2\end{array}$}} & \multirow{2}{*}{\multicolumn{2}{|c|}{$\begin{array}{r}26 \text { weeks } \\
n=2\end{array}$}} \\
\hline & & & & & & \\
\hline Implants & \multicolumn{2}{|r|}{$\mathrm{n}=16$} & \multicolumn{2}{|r|}{$\mathrm{n}=16$} & \multicolumn{2}{|r|}{$\mathrm{n}=16$} \\
\hline \multirow{2}{*}{ Location } & Tibia & Femur & Tibia & Femur & Tibia & Femur \\
\hline & $\mathrm{n}=8$ & $\mathrm{n}=8$ & $\mathrm{n}=8$ & $\mathrm{n}=8$ & $\mathrm{n}=8$ & $\mathrm{n}=8$ \\
\hline \multirow{3}{*}{ Coating } & \multicolumn{2}{|c|}{ Control $\mathrm{n}=4$} & \multicolumn{2}{|c|}{ Control $\mathrm{n}=4$} & \multicolumn{2}{|c|}{ Control $\mathrm{n}=4$} \\
\hline & \multicolumn{2}{|c|}{ Titanium $\mathrm{n}=6$} & \multicolumn{2}{|c|}{ Titanium $\mathrm{n}=6$} & \multicolumn{2}{|c|}{ Titanium $\mathrm{n}=6$} \\
\hline & \multicolumn{2}{|c|}{$\mathrm{CaP} n=6$} & \multicolumn{2}{|r|}{$\mathrm{CaP} n=6$} & \multicolumn{2}{|r|}{$\mathrm{CaP} n=6$} \\
\hline
\end{tabular}

Animal preparation and anesthesia

All animals received human care in compliance with the FELASA guidelines and recommendations. The study was approved by the Ethical Committee for Animal Research at Medanex Clinic (EC MxCl-2012-010).

At first, animals were sedated with an intravenous (IV) injection of $0.1 \mathrm{mg} / \mathrm{kg}$ xylazine (Xyl-M 2\%; V.M.D.nv/sa, Arendonck, Belgium). Induction of anesthesia was obtained by an injection of $0.2 \mathrm{mg} / \mathrm{kg}$ midazolam IV (Dormicum, N.V. Roche S.A., Brussels, Belgium) and $4 \mathrm{mg} / \mathrm{kg}$ ketamine IV (Ketamine 1000 CEVA, Ceva Santé Animale, Brussels, Belgium). Animals were intubated with a cuffed endotracheal tube (internal diameter of 7-8 mm) (Kruuse, Langeskov, Denmark). The animal was placed in supine position on the operating table, and connected to the mechanical ventilator. Anesthesia was maintained with 1.5\%-2\% isoflurane (IsoFlo, Ecuphar, Oostkamp, Belgium). Mechanical ventilation was provided with a volume-controlled ventilator $(\mathrm{Ci}-$ cero; Dräger, Lübeck, Germany) at a tidal volume of 8-10 $\mathrm{mL} / \mathrm{kg}$ body weight with an inspiratory oxygen fraction $\left(\mathrm{FiO}_{2}\right)$ of 0.5 .

ECG electrodes and saturation probe were attached and a venous catheter was inserted in the left jugular vein for administration of fluids and drugs. Each sheep received $2.2 \mathrm{mg} / \mathrm{kg}$ ceftiofur IV (Excenel, Pfizer Animal Health S.A., Louvain-la-Neuve, Belgium) and 40,000 IU/kg Natriumbenzylpenicilline IV (Penicilline, Kela, Sint-Niklaas, Belgium) per operatively.

The operation field was scrubbed with chloorhexidine digluconate (Hibiscrub, Regent Medical, Manchester, UK) and disinfected with an antiseptic solution of ethanol 96\% (Stella, VWR, Haasrode, Belgium). Thereafter, the sheep was draped.

\section{Implantation of cylindrical dowels and postoperative follow-up}

Firstly, an incision was made at the left distal lateral femur. Two uni-cortical defects were created by using a surgical, sterile motor and a drill $\mathrm{n}^{\circ}$. Two dowels, randomly chosen, were inserted. The subcutis was sutured with an absorbable suture 2.0 (Vicryl, 
Johnson and Johnson Intl., St-Stevens Woluwe, Belgium). The skin was sutured with a non-absorbable suture 2.0 (Ethilon, Johnson and Johnson Intl., StStevens Woluwe, Belgium).

This procedure was repeated at the right distal lateral femur and at the left and right proximal medial tibia.

Postoperatively, all animals were checked daily by an experienced veterinarian. Rectal temperature (d0-d7) was measured, wounds were disinfected and evaluated (d0-d14) and weight bearing was evaluated. Antibiotics, $2.2 \mathrm{mg} / \mathrm{kg}$ ceftiofur IV (Excenel, Pfizer Animal Health S.A., Louvain-la-Neuve, Belgium) were administered daily for 5 days. Analgesia, $0.005 \mathrm{mg} /$ kg buprenorphin (Vetergesic, Ecuphar, Oostkamp, Belgium) was administered twice a day during 3 days, or 5 days if needed.

\section{Euthanasia and retrieval of the dowels}

Two animals were sacrificed after 6 weeks, 2 animals after 12 weeks and 2 animals after 26 weeks of followup. After induction of general anesthesia by an injection of $0.2 \mathrm{mg} / \mathrm{kg}$ midazolam IV (Dormicum, N.V. Roche S.A., Brussels, Belgium) and $4 \mathrm{mg} / \mathrm{kg}$ ketamine IV (Ketamine 1000 CEVA, Ceva Santé Animale, Brussels, Belgium), animals were euthanized by an IV injection of T61 (Intervet International B.V., Brussels, Belgium). Implants surrounded by a cube of bone tissue were explanted and stored in formaldehyde $4 \%$ for 48 hours. Thereafter, bone samples were stored in ethanol $(80 \%)$ until further analysis $(\mu \mathrm{CT}$ and histology).

\section{Micro-Computed Tomography}

All micro-computed tomography $(\mu \mathrm{CT})$ analyses have been done by an independent third party reviewer blinded to the study protocol.

At each time point $(6,12$, and 26 weeks after implantation) 16 samples, containing the implant were explanted from the sheep's tibia or femur and scanned with a $\mu \mathrm{CT}$ scanner, providing $563 \mathrm{D}$ images of resolution $7.5 \times 7.5 \times 7.5 \mu \mathrm{m}^{3}$.

The first step in the quantitative analysis is the detection of the cylindrical dowel in the images, which is performed by the combination of a circular Hough transform and linear curve fitting (Figure 1).

To measure the global bone-implant contact (BIC), a cylindrical slice is sampled at a constant distance of 30 voxels or $225 \mu \mathrm{m}$ from the implant surface. For visualization purposes, this slice could be stratified, as shown in Figure 2. It is, thus, a representation of the first shell around the dowel.

The BIC is then defined as the percentage of bone pixels within this slice. A pixel is classified as bone, using a threshold that best separates bone from nonbone tissue based on the image histograms.

Next, 60 volumes of interest (VOIs) are determined around the implant (5 layers of 12 segments), as illustrated by Figure 3 .

\section{Statistics}

All statistical analyses have been done by an independent third party reviewer blinded to the study protocol.

The data were analyzed using ANOVA models. The dependent variables are metric so a 2 factorial ANOVA model was applied containing two between the factors of dowel type and time.

The image analysis applied to the three different tested dowel-groups resulted in a data series covering

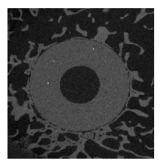

a

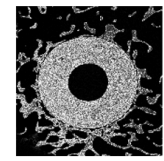

b

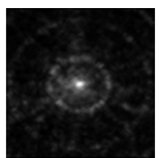

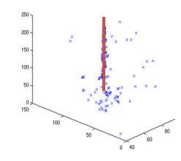

Fig. 1. Detection of the cylindrical dowel with original image (a), dowel probability map (b), Hough transformed image (c), and line fitting through the maxima of the Hough images (d).
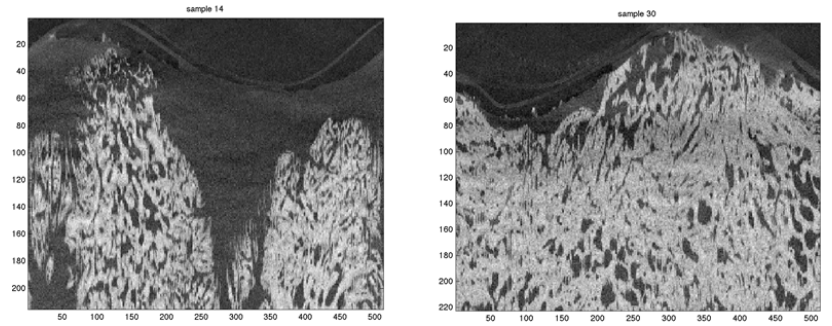

Fig. 2. Images sampled at 30 voxels from the implant surface and stratified for visualization. 
healing in a 26 week period. Observations are available for 3 moments in time: 6 weeks, 12 weeks and 26 weeks post-surgery. In order to reduce the effect of outliers and general variability, the 24 images/data points available per dowel were averaged to obtain one single measurement for BIC and bone volume/ tissue volume (BV/TV).

\section{Histology}

Histology was done by a third party, who was blinded to the study protocol.

After initial storage in ethanol $80 \%$, further dehydration in a graded series of ethanol namely $80 \%, 90 \%$, 94\% and methanol was executed. Thereafter, the samples were placed in a recipient with methylmetacrylate, followed by hardening during a few weeks. Once the methylmetacrylate was hardened, sawing was performed under constant water cooling. Sections (of a thickness of $120 \mu \mathrm{m}$ approximately) were sawn with a diamond blade. All samples were polished to a thickness of approximately $50 \mu \mathrm{m}$ and stained with Stevenel's blue and Von Gieson's picrofuchsin. Every dowel leaded to 3 sections. The histologic examination of the sections was performed using light microscopy.

\section{Results}

Animal study and explantation of dowels

All animals underwent anesthesia without problems and recovered well.

No infections occurred and fever was absent. In the

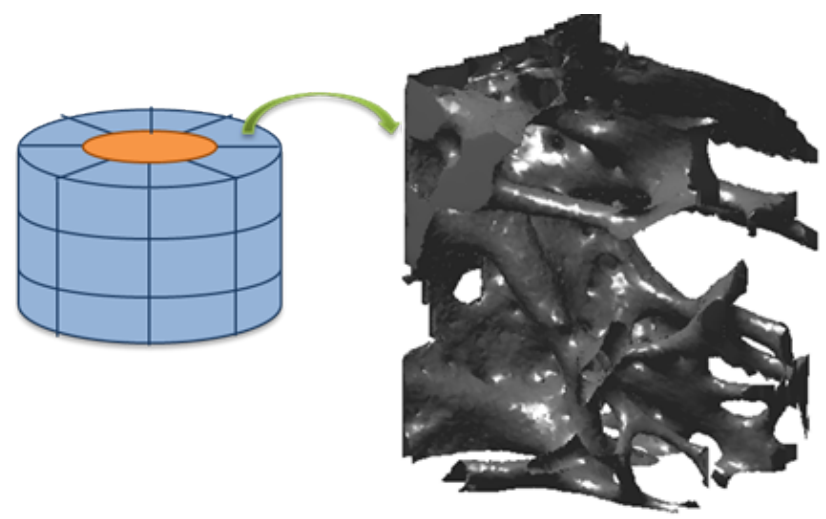

Fig. 3. Volumes of interest (blue) around the dowel (orange). In this figure, 24 VOls are drawn (3 times 8). In our analysis we use $60 \mathrm{VOls}$ (5 times 12). beginning, weight bearing was only $50 \%$ in $3 / 6$ sheep. In all sheep, small to large swellings were seen at the different operation sites in the early post-operative period. After 14 days, swellings were reduced and weight bearing was normal in all sheep.

Two animals were sacrificed after 6 weeks, 2 animals after 12 weeks and 2 animals after 26 weeks of followup and dowels were explanted. Due to overgrowth with bone tissue, some of the dowels were hit during sawing out.

\section{Micro-Computed Tomography}

In total, 48 samples (8 implants, 6 sheep) were analyzed quantitatively.

In the figure below, a representative slice of each group is given. Visually, the samples with highest bone integration are from the titanium group (Figure $4 a)$ and CaP group (Figure 4b); the lowest bone integration is attained for the control group (Figure 4c).

\section{Statistics}

No significant difference was seen after a complete analysis of BIC over time in the three groups (Figure 5).

However, in a more focused analysis, the interaction component for 6 to 12 weeks data becomes significant between the titanium group and the control group: $\mathrm{F}(1 ; 16)=5.7075, \mathrm{p}=0.02956$ (Figure 6).

Regarding BIC, no significant differences were seen between the titanium group and the $\mathrm{CaP}$ group.

Similar results were observed for BV/TV: no significant differences after a complete analysis of BV/TV over time in the three groups(Figure 7).

A significant difference in $\mathrm{BV} / \mathrm{TV}$ between the titani-

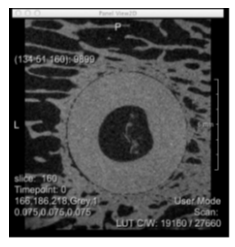

a

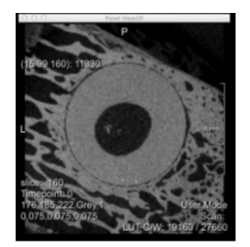

b

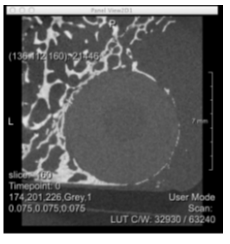

C
Fig. 4. Representative slices for titanium, (A), $\mathrm{CaP},(B)$ and control (C). 
um group and the control was observed in the 6 to 12

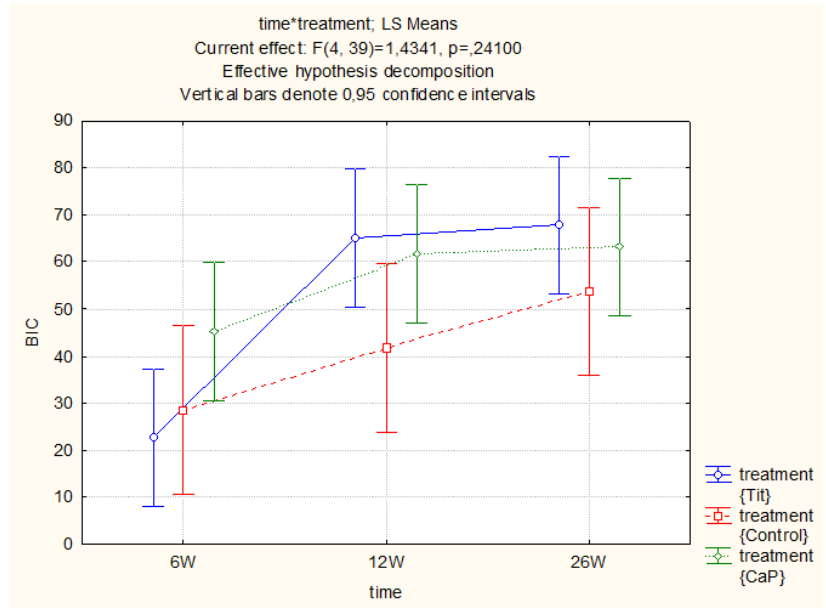

Fig. 5. Time * Treatment statistics for $B I C$ in the 6 to 26 weeks period. No significant differences were observed $(p=0.24100)$.

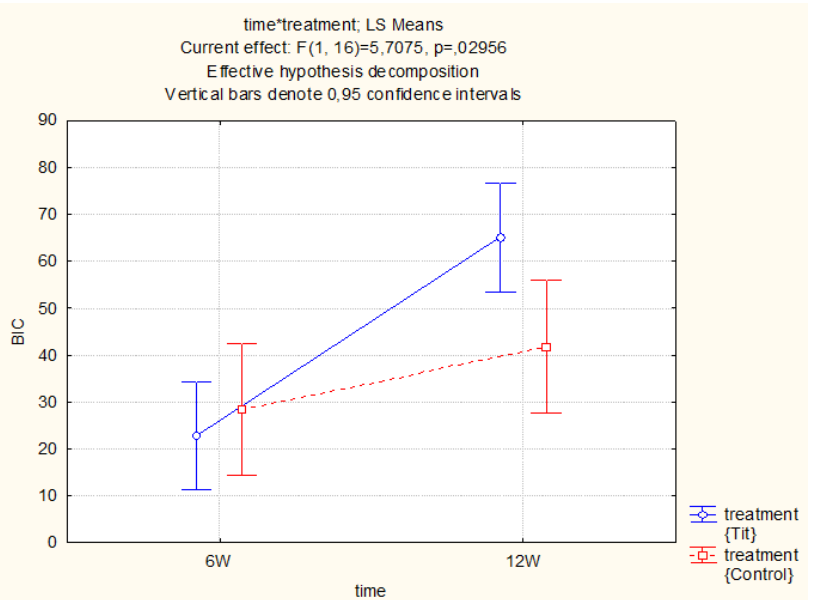

Fig. 6. Time * Treatment statistics for BIC in the 6 to 12 weeks period. BIC was significantly higher in the titanim group compared to the control.

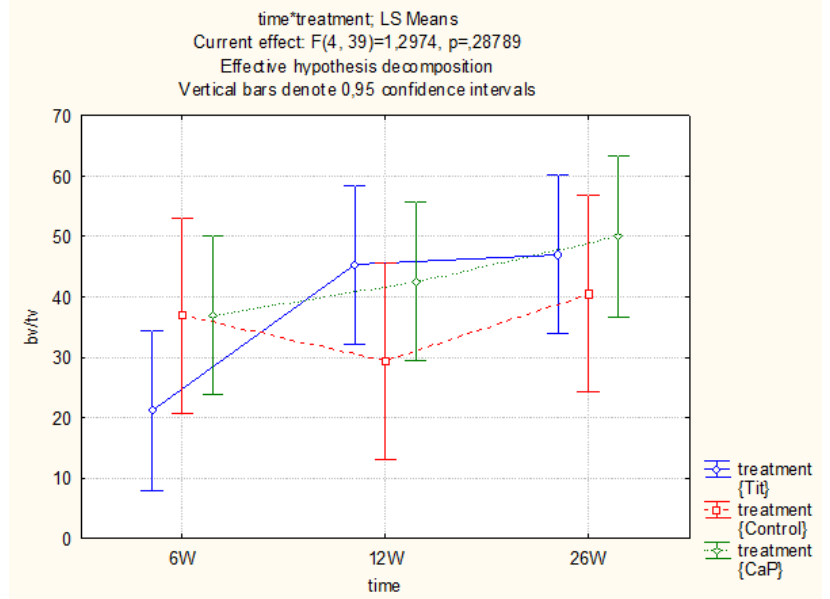

Fig. 7. Time * Treatment statistics for BV/TV in the 6 to 26 weeks period. No significant differences were observed $(p=0.28789)$. weeks period $(\mathrm{p}=0.02301)($ Figure 8$)$.

No significant differences were seen for BV/TV between the titanium group and $\mathrm{CaP}$.

In Table 2 and Table 3 descriptive information on $\mathrm{BIC}$ and BV/TV, respectively, is shown.

A strong positive correlation $(\mathrm{r}=0.85, \mathrm{p}<0.05)$ was observed between BIC and BV/TV (see Figure 9).

Histology

In order to illustrate the results obtained by means of $\mu \mathrm{CT}, 1$ implant of each group (titanium, $\mathrm{CaP}$ and control), were used for histological analysis (Figure 10). On the sections of titanium and $\mathrm{CaP}$, direct bone implant contact was seen (Figure 10a and Figure 10b,

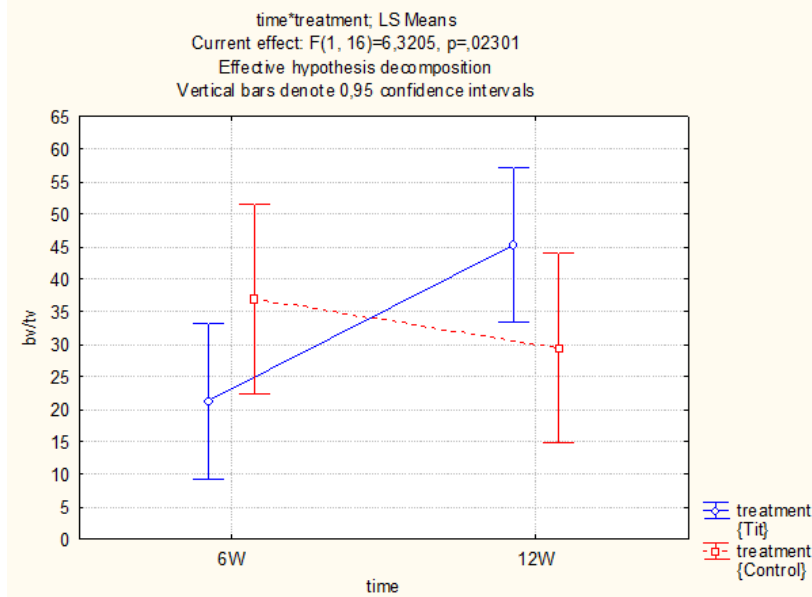

Fig. 8. Time * Treatment statistics for BIC in the 6 to 12 weeks period. BIC was significantly higher in the titanium group compared to the control.

Table 2. Descriptive information on bone implant contact.

\begin{tabular}{|l|r|r|r|r|}
\hline BIC & & $\mathbf{6}$ weeks & $\mathbf{1 2}$ weeks & $\mathbf{2 6}$ weeks \\
\hline Titanium & $\mathrm{N}$ & 6 & 6 & 6 \\
\hline & Mean & 22.783 & 65.040 & 67,902 \\
\hline CaP & $\mathrm{N}$ & 6 & 7.228 & 7.228 \\
\hline & Mean & 45.170 & 61.663 & 63.184 \\
\hline & Std.Err. & 7.228 & 7.228 & 7.228 \\
\hline Control & $\mathrm{N}$ & 4 & 4 & 4 \\
\hline & Mean & 28.437 & 41.670 & 53.793 \\
\hline & Std.Err. & 8.852 & 8.852 & 8.852 \\
\hline
\end{tabular}


respectively). The surface of the implant was covered with bone trabeculae; whereas on the sections of the control a fibrotic layer was seen between the dowel and the surrounding bone tissue (Figure 10c). Areas of cartilage were present as well in the control. These histological findings are a tool to confirm the results obtained with the analysis of all data by $\mu \mathrm{CT}$ and approved with a statistical analysis using ANOVA models concentrating on BIC and BV/TV.

\section{Discussion}

In this animal study, long bones of sheep (femur and tibia) were implanted with coated and uncoated (control) dowels to assess the effect of nanocoating of PEEK on the adhesion of bone.

\begin{tabular}{|c|c|c|c|c|}
\hline $\mathrm{BV} / \mathrm{TV}$ & & 6 weeks & 12 weeks & 26 weeks \\
\hline \multirow[t]{3}{*}{ Titanium } & $\mathrm{N}$ & 6 & 6 & 6 \\
\hline & Mean & 21.217 & 45.236 & 47.036 \\
\hline & Std.Err. & 6.538 & 6.538 & 6.538 \\
\hline \multirow[t]{3}{*}{$\mathrm{CaP}$} & $\mathrm{N}$ & 6 & 6 & 6 \\
\hline & Mean & 37.027 & 42.533 & 49.995 \\
\hline & Std.Err. & 6.538 & 6.538 & 6.538 \\
\hline \multirow[t]{3}{*}{ Control } & $\mathrm{N}$ & 4 & 4 & 4 \\
\hline & Mean & 36.889 & 29.315 & 40.498 \\
\hline & Std.Err. & 8.007 & 8.007 & 8.007 \\
\hline
\end{tabular}

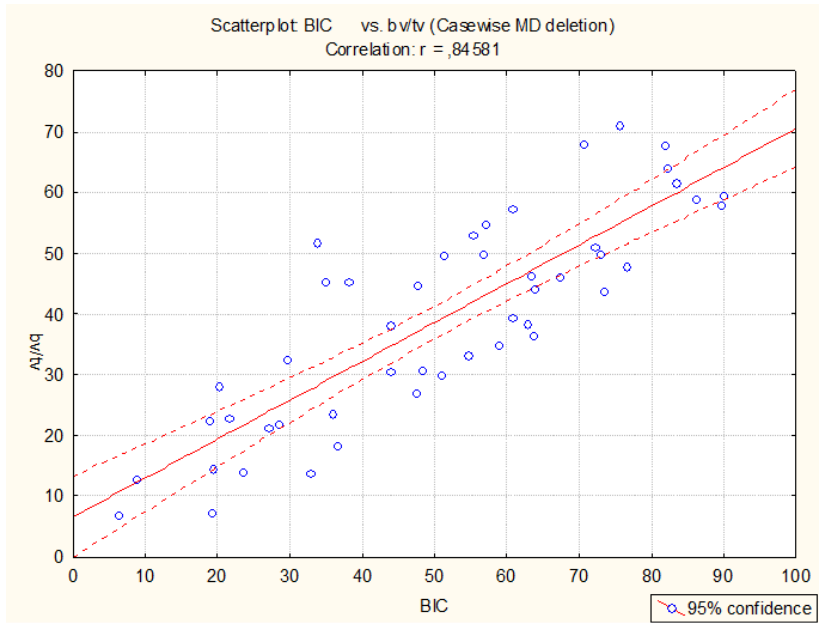

Fig. 9. Correlation between BIC and BV/TV.
We have demonstrated that coating of PEEK dowels with a nanocoating of titanium has beneficial effects on adhesion of bone tissue. A strong correlation was seen between BIC and BV/TV.

Both BIC and BV/TV were significantly higher in the titanium group versus the control group in the 6 to 12 weeks period.

PEEK materials are widely used in orthopedic and especially spine surgery. PEEK has good mechanical properties; however the adhesion of PEEK implants to bone tissue proceeds slowly because of their inert properties. ${ }^{7}$ Several techniques exist to modify the surface of implantable devices in order to enhance the bioactivity. Khoury et al. developed a new accelerated neutral atom beam technique. The obtained texture seemed to be advantageous for cell attachment and proliferation. ${ }^{7}$ Another group described that formation of a sol-gel-formed calcium phosphate film, identified as a poorly crystallized hydroxyapatite layer, over titanium implants had a significantly beneficial effect on the rate of bone ingrowth into the porous region thereby resulting infaster implant fixation and osseointegration. ${ }^{8}$

To our knowledge, we are the first to combine a nanocoating of titanium and calcium phosphate with the PEEK material in order to combine the advantages of different materials.

In this study, the sheep was chosen because of several advantages, related to this animal model. Compared to pigs, sheep are easy to house and to handle, which is very beneficial during the post-operative period. ${ }^{9}$ Clinical examinations, temperature measurements, wound care etc. are much easier to perform in

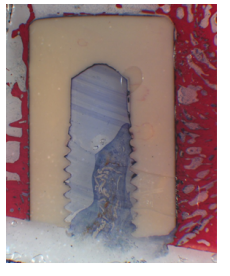

a

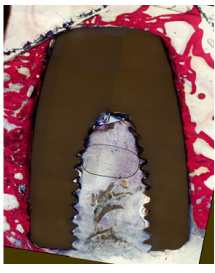

b

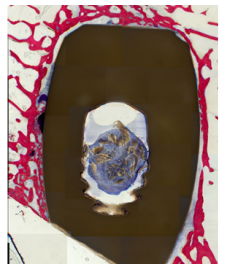

c
Fig. 10. Histological sections stained with Stevenel's blue and Von Gieson's picrofuchsin of (a) titanium with direct bone implant contact, (b) $\mathrm{CaP}$ with direct bone implant contact (c) Control presence of cartilage tissue and fibrotic layers between the dowel and the surrounding bone tissue. 
sheep compared to pigs which are stressed and agitated more easily. Pigs were less suitable for this study with long term follow-up period due to their large growth rate as well.

In contradiction with goats, which often stand on their hind legs, the weight bearing of sheep is more equally divided over their 4 legs, which leads to more uniform loading of the implants. In sheep, there is also more inter-animal uniformity, compared to goats, which makes it easier to standardize the procedure.

Furthermore, the body weight of adult sheep is more similar to humans compared to rabbits or dogs. ${ }^{10}$ For large animals, such as sheep, ISO recommended dimensions of cylindrical implants are stated to be 4 $\mathrm{mm}$ in diameter and $12 \mathrm{~mm}$ in length for implantation in femur and tibia. ${ }^{9}$ In this study, 2 implants (8 $\mathrm{mm}$ diameter and $12 \mathrm{~mm}$ length) were implanted in femur and tibia, both left and right. The size of the sheep allowed this number and dimensions of implants. This was tested in an ex vivo try out prior to the start of the main study.

Another reason to choose the sheep as animal model was related to the future studies that are planned to be executed. The next step in this research is to implant orthopedic cages between cervical vertebrae. Therefore the human anatomy of the cervical spine was compared to that of different animal species. Several studies have shown similarities between sheep and human regarding cervical spine. ${ }^{11,12}$ Kandiorza et al. stated that the use of sheep cervical spine is suited as a model for cervical spine research. Especially the sheep motion segment C3-C4 seemed to be a reliable model for the corresponding human motion segment. ${ }^{13}$

At this stage, however, the main focus was BIC and $\mathrm{BV} / \mathrm{TV}$ and therefore long bones (femur and tibia) were the preferred location for implantation. This procedure is less complex in comparison with implantation at the location of the spine, bones are easily accessible and surgery is less invasive for the animal. Now it has been shown that the coating with Titanium has a beneficial effect on the adhesion of bone tissue. The next phase of the study will consist of a series of implantations in an orthotopic sheep model. $\mu \mathrm{CT}$ was used in this study for analysis of BIC and $\mathrm{BV} / \mathrm{TV}$ for different reasons. Holdsworth and Thornton already pointed out that $\mu \mathrm{CT}$ has the potential to replace histology. ${ }^{14} \mu \mathrm{CT}$ is known to be a nondestructive technique, in comparison with the conventional approach to morphologic measurements (histology) which entails substantial preparation of the specimen, including embedding in methylmethacrylate, followed by sectioning into slices. The destructive nature of the histology procedure makes it impossible to use the same samples for other measurements such mechanical testing.

Also for assessing the morphometry of bone, $\mu \mathrm{CT}$ has many advantages over histology, since it allows a fast and very precise procedure to quantification of cancellous and compact bone. ${ }^{15}$ Moreover, automated processing techniques can calculate three-

dimensional morphometric indices (like bone density, bone surface density, bone implant contact, etc.), providing a better and more complete image of the bone morphometry.

In this study, we decided to perform histological analysis on some of the samples in order to be able to visualize it in the conventional way as well. However, this was only as an illustration. We did this only to support the results of $\mu \mathrm{CT}$, since the majority of physicians is familiar with histology rather than with $\mu \mathrm{CT}$ analyses. The number of samples analyzed by histology was too small to analyze in a statistical way.

Regarding explantation of the implants some remarks need to be made: some of the implants were very difficult to localize due to overgrowth with bone tissue. In that case, fluoroscopy was used to visualize and localize the implants. Due to overgrowth of bone tissue, some of the dowels were hit during sawing out. If this was the case, and only a partial implant was available for $\mu \mathrm{CT}$, only the part of the implant that was unaffected was taken into account.

No significant differences were noticed for BIC and $\mathrm{BV} / \mathrm{TV}$ after complete analysis over time in the 3 study groups. The fact that we note a significant interaction effect $(\mathrm{p}=0.030)$ for BIC in the 6-12 week period comparing the titanium group with the control while the interaction effect for the entire study 
period including all groups is not significant $(\mathrm{p}=0.241)$ can be explained by looking at the observed power in both situations. The observed power (the ability to detect an effect if the effect exits) for the full model equals 0,403 , while it increases to 0,612 for the more focused analysis.

However, a trend towards significance was observed between the titanium group and the control group in the 6 to 12 weeks period. Therefore we decided to perform a more focused analysis. This additional analysis confirmed the trend that was noticed in the beginning. The small number of animals used in the study, can be a possible explanation why no significant differences were observed is the overall analysis.

A significant difference in $\mathrm{BV} / \mathrm{TV}$ and $\mathrm{BIC}$ between the titanium group and the control group was observed in the 6 to 12 weeks period, which indicates a faster and more active osseointegration process in the dowels coated with titanium. Such significant differences were not observed between the $\mathrm{CaP}$ group and the control group, and the titanium group and the $\mathrm{CaP}$ group, respectively.

We realize that the low number of animals is a limitation of the study. However, even in this low number, significant differences were already observed. We believe that, with larger study groups, more significant results could be obtained after a complete analysis of $\mathrm{BIC}$ and $\mathrm{BV} / \mathrm{TV}$ over time in the three groups.

In the control group, a layer of cartilage tissue was observed between the implant and the bone tissue. This presence of cartilage tissue is an indication of a dysfunctional bone formation.

We believe that a nanocoating of PEEK implants with titanium stimulates bone-implant integration and that the surface treatment triggers significant more and earlier bone on-growth.

\section{Conclusion}

In conclusion, nanocoating of PEEK implants with titanium, but not $\mathrm{CaP}$, enhanced biocompatibility of PEEK in a heterotopic sheep model. This study was a first step in testing the effects of a nanocoating with titanium of PEEK implants on bone formation.

For future experiments, it would be interesting to further investigate the beneficial effects of a titanium coating versus control PEEK implants in an orthotopic sheep model.

With an orthotopic model, we would like to demonstrate lower cage migration and subsidence rates after fusion treatment of the vertebral spine.

\section{Acknowledgements}

The authors would like to thank Dr. Piet Delport for performing the surgeries and Prof. Dr. Evert Schepers for his help regarding the histological analysis.

This work was funded by Orthobion $\mathrm{GmbH}$, Konstanz, Germany which developed the technology of fine osseointegrative coating applied on the implants. The funder had no role in study design, data collection and analysis. The funder had a role in the preparation of the manuscript and decision to publish.

\section{References}

1. Kurtz SM, Devine JN. PEEK materials in trauma, orthopedic, and spinal implants. Biomaterials 2007;28:4845-69.

2. Hunter A, Archer CW, Walker PS, Blunn GW. Attachment and proliferation of osteoblasts and fibroblasts on biomaterials for orthopaedic use. Biomaterials 1995;16:287-95.

3. Suchenski M, McCarthy MB, Chowaniec D, Hansen D, McKinnon W, Apostolakos J, et al. Material properties and composition of soft-tissue fixation. Arthroscopy 2010;26:821-31.

4. Ha SW, Mayer J, Koch B, Wintermantel E. Plasma-sprayed hydroxylapatite coating on carbon fibre reinforced thermoplastic composite material. J Mater Sci 1994;5:481-4.

5. Schroder K, Meyer-Plath A, Keller D, Ohl A. On the applicability of plasma assisted chemical micropatterning to different polymeric biomaterials. Plasmas Polym 2002;7:103-25.

6. Noiset O, Schneider YJ, Marchand-Brynaert J. Adhesion and growth of $\mathrm{CaCo} 2$ cells on surfacemodified PEEK substrata. J Biomat Sci-Polym E 
2000;11:767-86.

7. Khoury J, Kirkpatrick SR, Maxwell M, Cherian RE, Kirkpatrick A, Svrluga RC. Neutral atom beam technique enchances bioactivity of PEEK. Nucl Instrum Meth B 2013;307:630-4.

8. Nguyen HQ, Deporter DA, Pilliar RM, Valiquette N, Yakubovich R. The effect of sol-gel-formed calcium phosphate coatings on bone ingrowth and osteoconductivity of porous-surfaced Ti alloy implants. Biomaterials 2004;25:865-76.

9. Pearce AI, Richards RG, Milz S, Schneider E, Pearce SG. Animal models for implant biomaterial research in bone: A review. Eur Cells Mater

2007;13:1-10.

10. Newman E, Turner AS, Wark JD. The potential of sheep for the study of osteopenia: current status and comparison with other animal models. Bone 1995;16:S227-84.

11. Cain CCMJ, Fraser RD. Bony and vascular anatomy of the normal cervical spine in the sheep. Spine 1995;20:759-65.

12. Sheng SR, Wang XY, Xu HZ, Zhu GQ, Zhou

YF. Anatomy of large animal spines and its comparison to the human spine: a systematic review. Eur Spine J 2010;19:46-56.

13. Kandziorza F, Pflugmacher R, Scholz M, Schnake K, Lucke M, Schröder R, Mittlmeier T. Comparison between sheep and human cervical spines. An anatomic, radiographic, bone mineral density, and biomechanical study. Spine 2001;26:1028-37.

14. Holdsworth DW, Thornton MM. Micro-CT in small animal and specimen imaging. Trends Bio Technol 2002;20:34-9.

15. Muller R, Van Campenhout H, Van Damme B, Van Der Perre G, Dequeker J, Hildebrand T, et al. Morphometric analysis of human bone biopsies: a quantitative structural comparison of histological section and micro-computed tomograph. Bone 1998;23:59-66.

\section{Disclosures}

The authors declare no relevant financial disclosures.

\section{Corresponding Author}

Caroline Meers, DVM, PhD, Medanex, Heggestraat 10, Diest, 3290, Belgium. caro-

line.meers@medanex.com.

Published 17 July 2015.

This manuscript is generously published free of charge by ISASS, the International Society for the Advancement of Spine Surgery. Copyright @ 2015 ISASS. To see more or order reprints or permissions, see http://ijssurgery.com. 